\title{
Experimental investigation of the effect of different process variables on the viscosity of sulfonated polyacrylamide copolymers
}

\author{
Saeed Akbari ${ }^{1} \cdot$ Syed M. Mahmood ${ }^{1} \cdot$ Isa M. Tan $^{2} \cdot$ Abhilash M. Bharadwaj $^{3}$. \\ Hamed Hematpour ${ }^{1}$
}

Received: 25 October 2015/Accepted: 13 March 2016/Published online: 23 April 2016

(C) The Author(s) 2016. This article is published with open access at Springerlink.com

\begin{abstract}
Increasing the viscosity of injected water by the addition of polymer improves the displacement efficiency during the water flooding process. In this study, a sulfonated polyacrylamide copolymer has been added to salt water. Several parameters, such as polymer concentration, shear rate, $\mathrm{NaCl}$ concentration, molecular weight and sulfonation degree, have a significant effect on the polymer solution viscosity. The main objective of this paper is to investigate how the polymer solution viscosity varies with changes in the input parameters so as to identify the relative importance of these parameters. This paper incorporates the Design of Experiments technique using Taguchi's method and the Analysis of Variance (ANOVA) to investigate the effect of process variables on the viscosity of a polymer solution. Five input parameters and six possible interactions have been investigated. The analysis of the experimental results revealed that two input parameters, namely, polymer concentration and shear rate, have the most significant impact on polymer viscosity. Two strong interactions were observed in the (1) $\mathrm{NaCl}$ concentration and sulfonation degree and (2) molecular weight and $\mathrm{NaCl}$ concentration studies. The results show that the Taguchi method was successful in identifying the main effects and interaction effects. ANOVA further buttresses the results
\end{abstract}

Saeed Akbari

akbari.sa70@gmail.com

1 Centre of Research in Enhanced Oil Recovery (COREOR), Petroleum Engineering Department, Universiti Teknologi Petronas, 32610, Tronoh, Malaysia

2 Fundamental and Applied Science, Universiti Teknologi Petronas, 32610, Tronoh, Malaysia

3 Petroleum Engineering Department, Universiti Teknologi Petronas, 32610, Tronoh, Malaysia from Taguchi's method by showing a strong similarity in its results.

Keywords Sulfonated polyacrylamide polymers . Polymer viscosity · ANOVA · Taguchi Method

\section{Introduction}

Polymers find great usage in the oil and gas industry. Their applicability in profile modification, enhanced oil recovery (EOR), drilling, etc., makes them highly versatile in the industry. Water flooding involves the injection of water into the reservoir to sustain pressure and dislodge the oil. Unstable displacement may be noticed in this process given that oil usually has a higher viscosity than water. The displacement efficiency in the water flooding technique can be improved by adding a polymer to the injected water. This addition increases the water viscosity and, in turn, displacement efficiency. The mobility ratio $(M)$ is used to explain this enhancement of the water flooding efficiency technique. The mobility ratio is understood as a combination of oil and water viscosities along with the effective permeability as shown in the following equation:

$M=\frac{K_{\mathrm{w}} \mu_{\mathrm{o}}}{K_{\mathrm{o}} \mu_{\mathrm{w}}}$

where $K_{\mathrm{o}}$ and $K_{\mathrm{w}}$ are the effective permabilities to oil and water, and $\mu_{\mathrm{w}}, \mu_{\mathrm{o}}$ are the viscosity of water and oil, respectively (Sorbie 1991). It is noted that for a given reservoir condition, $M$ increases the recovery of oil prior to the water break decrease in the producing well. Given that the polymer increases the viscosity and reduces the relative permeability of the water, there is a subsequent decrease in $M$ as seen from Eq. 1. This, in turn, improves the oil 
recovery. As a result of the lower $M$, flow resistance builds up in the reservoir at the regions of the polymer penetration and the injected water will eventually enter into unswept zones (Needham and Doe 1987).

Several studies have been conducted, comprehensively and at length, on the viscosity of polymers, such as polyacrylamide (PAM), hydrolyzed polyacrylamide (HPAM), biopolymers, etc. (Bendell et al. 1989; Carreau 1972; Chagas et al. 2004; Dong et al. 2008). Synthetic polymers, such as HPAM, are used in EOR processes as seen in the Daqing and Bohai oil fields with a low concentration of salinity and hardness (Dong et al. 2008; Han et al. 2006). HPAM polymer is seen to have lower efficiency for reservoirs having high salt content while it yields a good outcome in low salinity reservoirs. These polymers also undergo shear degradation under high salinity conditions. The shear thinning behavior is significantly affected by the degree of hydrolysis, polymer concentration, molecular weight and temperature for polyacrylamide and HPAM polymers (Lewandowska 2007). Studies on polymer flooding also indicate the usage of biopolymers, such as Xanthan gum (Levitt and Pope 2008). Xanthan gum, in comparison to HPAM, offers higher resistance to shear degradation and high tolerance to salt and divalent ions. Nonetheless, biodegradation and injectivity problems still persist in biopolymers (Nasr-El-Din 1992).

However, a copolymerization study of acrylamide (AM) with the sodium salt of 2-acrylamide-2-methyl propanesulfonate (AMPS) having a distinct sulfonation degree depicts that AM/AMPS maintains the viscosity of the polymer solution better than HPAM under high salinity conditions in the presence of calcium ions (Levitt and Pope 2008). For a flow rate under $1000 \mathrm{ft} /$ day in Berea sandstone, a high shear stability and no injectivity issues are reported for a specific PAM's polymer and various associating polymers. For the ageing time of 100 days at $93{ }^{\circ} \mathrm{C}$, the AM/AMPS copolymer with a $40 \%$ sulfonation degree had higher hydrolytic stability than HPAM (Schulz et al. 1987). Although AM/AMPS copolymers proved their effectiveness as viscosifying agents, modeling and quantification of their viscosity still needs to be carried out. Therefore, these types of polymers have been considered for this study.

Literature shows that process variables, such as polymer concentration, shear-rate, sulfonation degree, salt concentration and molecular weight, have an influence on the polymer solution viscosity (Luo et al. 2006; Rashidi et al. 2011; Sheng 2011; Sorbie 1991). The main focus of this paper is to precisely assess the effects of the above-mentioned parameters on the polymer solution viscosity. Previous polymer flooding models and studies widely used the one-factor-at-a-time (OFAT) method, which is inconsistent. In this method, each parameter is evaluated across a range of values while keeping other parameters constant. The serious risk associated with the OFAT method is that the models developed through the OFAT are sensitive to just individual parameters. This means that it does not take into account the possibility of interactions among parameters. An interaction is said to exist between variables when the effect of one variable on the response depends on the level of another variable (Mathews 2005). Given that such interactions are common among the variables in the polymer flooding process, the OFAT seems unsuitable for modeling purposes.

Alternatively, the full-factorial method may be used for analyzing the parameter interactions. However, a large number of simulations are required by this method (Montgomery 2008). Given that each simulation is time consuming, running large numbers of them is highly impractical. A common industrial method used as an alternative is the Taguchi method. This method, being less time consuming and hence more practical, employs only a small number of all the possible combinations of the model parameters to estimate the main effects and some interactions. And the number of simulations is reduced by the orthogonal array (OA) technique (Taguchi 1987), without significant loss of information. As there is no evidence in the available literature about the study of the effect of polymer concentration, shear rate, sulfonation degree and molecular weight using the Taguchi method, this paper fills the gap using the method for the design of the experiment and analysis of the results.

Thus, the main objective of this work was to investigate the effects of all the parameters mentioned above on the polymer viscosity using Taguchi's method. Analysis of Variance (ANOVA) was also used to statistically assess the influence that each investigated factor had on the polymer solution viscosity. The main effect and interaction effect graphs were used for the analysis and interpretation of the experimental results.

\section{Taguchi method}

As the number of process parameters increases, the classical design of the experiment needs scads of experiments and, therefore, becomes highly arduous to use (Montgomery 2008). To reduce the amount of trials required, Taguchi developed a contrivance to enhance the quality of a system product. As mentioned earlier, using orthogonal arrays with only a few experiments, a large parameter space can be studied. The experimental results are converted to a signal-to-noise ratio $(S / N)$ to determine the quality characteristic deviation from the anticipated values; a larger $S / N$ ratio indicates better quality characteristics (Bendell et al. 1989; Ross 1996). The two primary goals 
that Taguchi's method achieves are: establishing optimal parameters for a product or process, and identifying the most influential factor by checking the contribution of each design parameter (Taguchi 1987). In this study, Minitab ${ }^{\circledR}$ V.16 software was used to implement Taguchi's method and the ANOVA analysis.

Table 1 Polymer characteristics

\begin{tabular}{lcc}
\hline Polymer $^{\mathrm{a}}$ & $\begin{array}{l}\text { Molecular weight } \\
\text { (Million Dalton) }\end{array}$ & $\begin{array}{l}\text { Sulfonation degree } \\
(\mathrm{mol} \%)\end{array}$ \\
\hline AN105 & 6 & 5 \\
AN113 & 8 & 13 \\
AN125VLM & 2 & 25 \\
AN125 & 8 & 25 \\
AN125VMH & 12 & 25 \\
AN132 & 8 & 32 \\
\hline
\end{tabular}

a The polymers in this study were supplied by SNF FLOERGER<smiles>CCCCCCC(=O)NC(C)(C)CS(=O)(=O)O[18O]</smiles>

Fig. 1 Sulfonated polyacrylamide polymers

\section{Experimental details and data analysis}

\section{Materials}

\section{Polymers}

This investigation focuses on six AM/AMPS copolymers having different ranges of sulfonation degrees and molecular weights. Table 1 shows the characteristics of the polymers supplied by SNF Floerger for this study. The molecular structure of typical AM/AMPS copolymers is illustrated in Fig. 1.

\section{Bulk solutions}

$\mathrm{NaCl}$ solutions, having concentrations between 0.1 and $10 \mathrm{wt} \%$ in water, were used as solvents while keeping the temperature constant at $20^{\circ} \mathrm{C}$.

\section{Experimental procedure}

\section{Solution preparation}

The polymer solution was prepared by stirring the sodium chloride solution at $720 \mathrm{rpm}$ and gradually adding the dry polymer powder along the side of the vortex. This was performed to prevent the formation of "fisheyes"-developed when polymer powder is not evenly wetted. To obtain a homogeneous polymer solution, the speed of the stirrer was reduced to medium and it was stirred for almost $90 \mathrm{~min}$ to ensure complete dissolution. The prepared standard polymer solution (5000 ppm) was then diluted to

Table 2 Different study parts and their corresponding levels

\begin{tabular}{|c|c|c|c|c|c|c|}
\hline Study parts & Level 1 & Level 2 & Level 3 & Level 4 & Level 5 & Level 6 \\
\hline Polymer concentration (ppm) & 100 & 1000 & 2500 & 3500 & 5000 & \\
\hline Shear rate $\left(\mathrm{s}^{-1}\right)$ & 10 & 32 & 100 & 315 & 1000 & \\
\hline Sulfonation degree (mol. \%) & 13 & 25 & 32 & & & \\
\hline Shear rate $\left(\mathrm{s}^{-1}\right)$ & 10 & 32 & 100 & 315 & 735 & 1000 \\
\hline $\mathrm{NaCl}$ concentration (wt\%) & 0.1 & 1 & 3 & 5 & 10 & \\
\hline Shear rate $\left(\mathrm{s}^{-1}\right)$ & 10 & 32 & 110 & 340 & 1000 & \\
\hline Sulfonation degree (mol. \%) & 5 & 13 & 25 & 32 & & \\
\hline $\mathrm{NaCl}$ concentration (wt\%) & 0.1 & 0.5 & 1 & 5 & & \\
\hline Sulfonation degree (mol. \%) & 5 & 13 & 32 & & & \\
\hline Polymer concentration (ppm) & 1500 & 2500 & 5000 & & & \\
\hline Molecular weight $(\mathrm{mDa})$ & 2 & 8 & 12 & & & \\
\hline $\mathrm{NaCl}$ concentration (wt\%) & 0.1 & 1 & 5 & & & \\
\hline
\end{tabular}


obtain a final polymer concentration ranging from 100 to 3500 ppm.

\section{Viscosity measurement}

The viscosity was measured using a rotary rheometer, Malvern Bohlin Gemini II Rheometer. The shear viscosity was measured for shear rates between 10 and $1000 \mathrm{~s}^{-1}$, in both increasing and decreasing progression at $20{ }^{\circ} \mathrm{C}$ on the polymer samples. Shear rate hysteresis was absent in all solutions studied.

\section{Experimental plan}

However, since two-factor interactions may be confounded with other two-factor interactions (Mathews 2005), an experimental plan was designed to evaluate each two-factor interactions, separately. The parameters and their levels for each study are indicated in Table 2.

\section{Analysis of the $S / N$ ratio}

To perform a thorough analysis of the experimental data, Taguchi suggests two distinct routes. First, the averaged results from the experiments are to be used as input data for the main effect and ANOVA analysis. Second, for the same steps of the analysis, Taguchi strongly recommends the use of signal-to-noise $(S / N)$ ratios. The $S / N$ ratio is a concurrent quality metric linked to the loss function (Bendell et al. 1989). The optimum set of operating conditions can be identified simply by looking into the variation within the $S / N$ ratio results. The signal-to-noise $(S / N)$ ratio can be generated by transforming the experimental observation.

The $S / N$ number is calculated for each experiment to find the effect of each variable on the output. Based on the type of characteristics, there are three prominent $S / N$ ratios available-Nominal is best, Smaller is better and Larger is better.

Table 3 Results of ANOVA for different studies

\begin{tabular}{|c|c|c|c|c|c|c|}
\hline Parameters & $\begin{array}{l}\text { Degrees of } \\
\text { freedom (DF) }\end{array}$ & $\begin{array}{l}\text { Sum of } \\
\text { squares (SS) }\end{array}$ & $\begin{array}{l}\text { Mean } \\
\text { squares (MS) }\end{array}$ & $F$ ratio & $P$ value & $\begin{array}{l}\text { Contribution } \\
(\%)\end{array}$ \\
\hline Shear rate $\left(\mathrm{s}^{-1}\right)$ & 4 & 94.57 & 23.642 & 9.12 & 0.000 & 4.2823 \\
\hline Polymer conc. (ppm) & 4 & 2072.34 & 518.084 & 199.84 & 0.000 & 93.84 \\
\hline Error & 16 & 0.10441 & 2.593 & & & 1.878 \\
\hline Total & 4 & 2208.39 & & & & \\
\hline Shear rate $\left(s^{-1}\right)$ & 5 & 68.3803 & 13.6761 & 2983.28 & 0.000 & 99.4045 \\
\hline Sulf. degree $(\mathrm{mol} \%)$ & 2 & 0.3638 & 0.1819 & 39.68 & 0.000 & 0.52885 \\
\hline Error & 10 & 0.0458 & 0.0046 & & & 0.066579 \\
\hline Total & 17 & 68.7899 & & & & \\
\hline Shear rate $\left(s^{-1}\right)$ & 4 & 62.479 & 15.6196 & 187.16 & 0.000 & 74.576 \\
\hline $\mathrm{NaCl}$ conc. (wt $\%$ ) & 4 & 19.965 & 4.9914 & 59.81 & 0.000 & 23.8306 \\
\hline Error & 16 & 1.335 & 0.0835 & & & 1.5935 \\
\hline Total & 24 & 83.779 & & & & \\
\hline $\mathrm{NaCl}$ conc. $(\mathrm{wt} \%)$ & 3 & 8.2273 & 1252.72 & 2.7424 & 0.000 & 83.4090 \\
\hline Sulfonation degree (mol\%) & 3 & 0.6595 & 136.23 & 0.2198 & 0.181 & 6.6860 \\
\hline Error & 9 & 0.9769 & 63.9 & 0.1085 & & 9.9038 \\
\hline Total & 15 & 9.8638 & & & & \\
\hline Polymer conc. (ppm) & 2 & 48.6042 & 24.3021 & 368.61 & 0.000 & 93.9667 \\
\hline Sulf. degree $(\mathrm{mol} \%)$ & 2 & 2.8570 & 1.4285 & 21.67 & 0.007 & 5.523451 \\
\hline Error & 4 & 0.2637 & 0.0659 & & & 0.5098 \\
\hline Total & 8 & 51.7249 & & & & \\
\hline $\mathrm{NaCl}$ conc. (wt\%) & 2 & 16.750 & 8.3750 & 10.57 & 0.025 & 54.427 \\
\hline $\mathrm{Mw}(\mathrm{mDa})$ & 2 & 10.854 & 5.4272 & 6.85 & 0.51 & 35.2688 \\
\hline Error & 4 & 3.171 & 0.7927 & & & 10.3038 \\
\hline Total & 8 & 30.775 & & & & \\
\hline
\end{tabular}


The following equations are used for the calculation of $S / N$ for the case of a specific target value of the performance characteristic:

$S N_{i}=10 \log \frac{\bar{y}_{i}^{2}}{s_{i}^{2}}$

where $\bar{y}_{i}$ is the mean value and $s_{i}$ is the variance and can be calculated as follows:

$\bar{y}_{i}=\frac{1}{N_{i}} \sum_{u=1}^{N_{i}} y_{i, n}$

$s_{i}^{2}=\frac{1}{N_{i}-1} \sum_{u=1}^{N_{i}}\left(y_{i, u}-\bar{y}_{i}\right)$

where $N_{i}, u, i$ and $y_{i}$ are the number of trials for experiment $i$, trial number, experiment number and the value of the performance characteristic for a given experiment, respectively.

To minimize the performance characteristic, following equation is used to define the $S / N$ ratio:

$S / N_{i}=-10 \log \left(\sum_{u=1}^{N_{i}} \frac{y_{u}^{2}}{N_{i}}\right)$

To maximize the performance characteristic, following equation is used to define the $S / N$ ratio:

$S / N_{i}=-10 \log \left[\frac{1}{N_{i}} \sum_{u=1}^{N_{i}} \frac{1}{y_{u}^{2}}\right]$

After calculating the $S / N$ ratio for each experiment, the average $S / N$ ratio value is calculated for each factor and level. As the goal of this work has been to achieve a higher viscosity value, the $S / N$ ratio formulation for maximizing the performance characteristics was used.

\section{Analysis of variance (ANOVA)}

To identify the design parameters that considerably affect the response, ANOVA was applied. For ANOVA calculations, the sum of the squared deviations (SST) was computed through the following equation as discussed by Yang and Tarng (Sorbie 1991):

$\mathrm{SS}_{\mathrm{T}}=\sum_{i=1}^{n}\left(\eta_{i}-\eta_{m}\right)^{2}$

Here, $n$ is the number of experiments, $\eta_{i}$ is the mean $S / N$ ratio for the $i$ th experiment and $\eta_{m}$ is the total mean $S /$ $N$ ratio. The two sources of the $\mathrm{SS}_{\mathrm{T}}$ were: the sum of the squared deviations $\left(\mathrm{SS}_{\mathrm{d}}\right)$ due to each design parameter and the sum of the squared error $\left(\mathrm{SS}_{\mathrm{e}}\right)$. Table 3 shows the ANOVA results of the polymer solution viscosity for different steps of this study.
Table 4 Polymer concentration and Shear rate: the order and conditions for the Taguchi design including the coded levels of each parameter

\begin{tabular}{|c|c|c|c|}
\hline S. no & $\begin{array}{l}\text { Polymer } \\
\text { conc. (ppm) }\end{array}$ & Shear rate $\left(\mathrm{s}^{-1}\right)$ & $\begin{array}{l}\text { Viscosity } \\
(\mathrm{mPa} s)\end{array}$ \\
\hline 1 & $100(1)$ & $10(1)$ & 1.4 \\
\hline 2 & $100(1)$ & $31.6228(2)$ & 1.3 \\
\hline 3 & $100(1)$ & $100.776(3)$ & 1.3 \\
\hline 4 & $100(1)$ & $316.228(4)$ & 1.1 \\
\hline 5 & $100(1)$ & $1000(5)$ & 1.1 \\
\hline 6 & $1000(2)$ & $10(1)$ & 3.9 \\
\hline 7 & $1000(2)$ & $31.6228(2)$ & 3.6 \\
\hline 8 & $1000(2)$ & $100.776(3)$ & 3.1 \\
\hline 9 & $1000(2)$ & $316.228(4)$ & 2.7 \\
\hline 10 & $1000(2)$ & $1000(5)$ & 2.4 \\
\hline 11 & $2500(3)$ & $10(1)$ & 12.3 \\
\hline 12 & $2500(3)$ & $31.6228(2)$ & 10.2 \\
\hline 13 & $2500(3)$ & $100.776(3)$ & 8.5 \\
\hline 14 & $2500(3)$ & $316.228(4)$ & 6.8 \\
\hline 15 & $2500(3)$ & $1000(5)$ & 5.4 \\
\hline 16 & $3500(4)$ & $10(1)$ & 21.7 \\
\hline 17 & $3500(4)$ & $31.6228(2)$ & 17.2 \\
\hline 18 & $3500(4)$ & $100.776(3)$ & 13.7 \\
\hline 19 & $3500(4)$ & $316.228(4)$ & 10.2 \\
\hline 20 & $3500(4)$ & $1000(5)$ & 7.6 \\
\hline 21 & $5000(5)$ & $10(1)$ & 53.5 \\
\hline 22 & $5000(5)$ & $31.6228(2)$ & 39.1 \\
\hline 23 & $5000(5)$ & $100.776(3)$ & 26.8 \\
\hline 24 & $5000(5)$ & $316.228(4)$ & 18.1 \\
\hline 25 & $5000(5)$ & $1000(5)$ & 12.6 \\
\hline
\end{tabular}

\section{Results and discussion}

\section{Effect of the polymer concentration and the shear rate on the polymer solution viscosity}

The resultant range of the experimental conditions, including their coded levels, can be observed in Table 4. In this step, the viscosity of AN125 in 5 weight percent (wt\%) $\mathrm{NaCl}$ as a function of the shear rate and the polymer concentration at $20^{\circ} \mathrm{C}$ has been considered.

The $S / N$ response graph for the polymer solution with viscosity as a function of the polymer concentration and the shear rate is depicted in Fig. 2. The main effects' plot in Fig. 2a suggests that there might be a significant effect associated with the polymer concentration as compared to the shear rate effect. This is justified by the fact that in a low polymer concentration $(<1000 \mathrm{ppm})$, the shear rate has almost no effect on polymer solution viscosity and this phenomenon reduces the average effectiveness of the shear rate. 
Fig. 2 Polymer concentration and shear rate a main effect, b interaction effect $\mathbf{a}$

Main Effects Plot for SN ratios

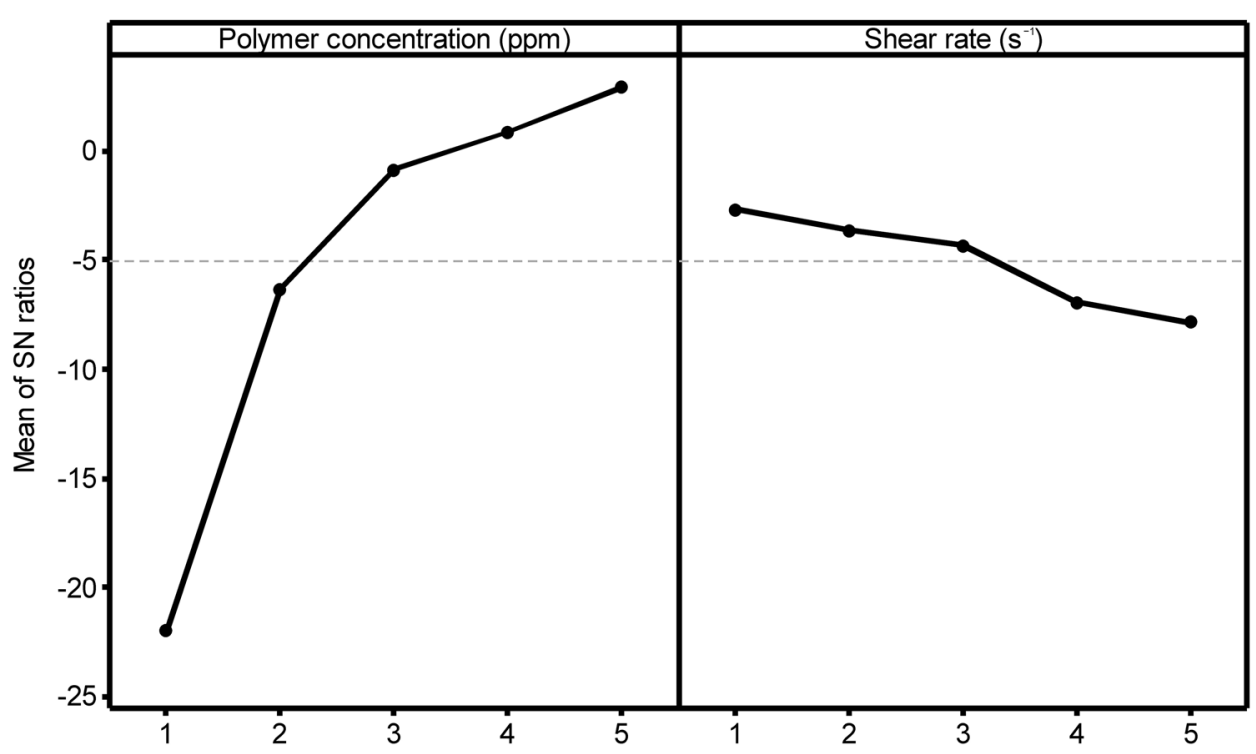

Signal-to-noise: Larger is better

b

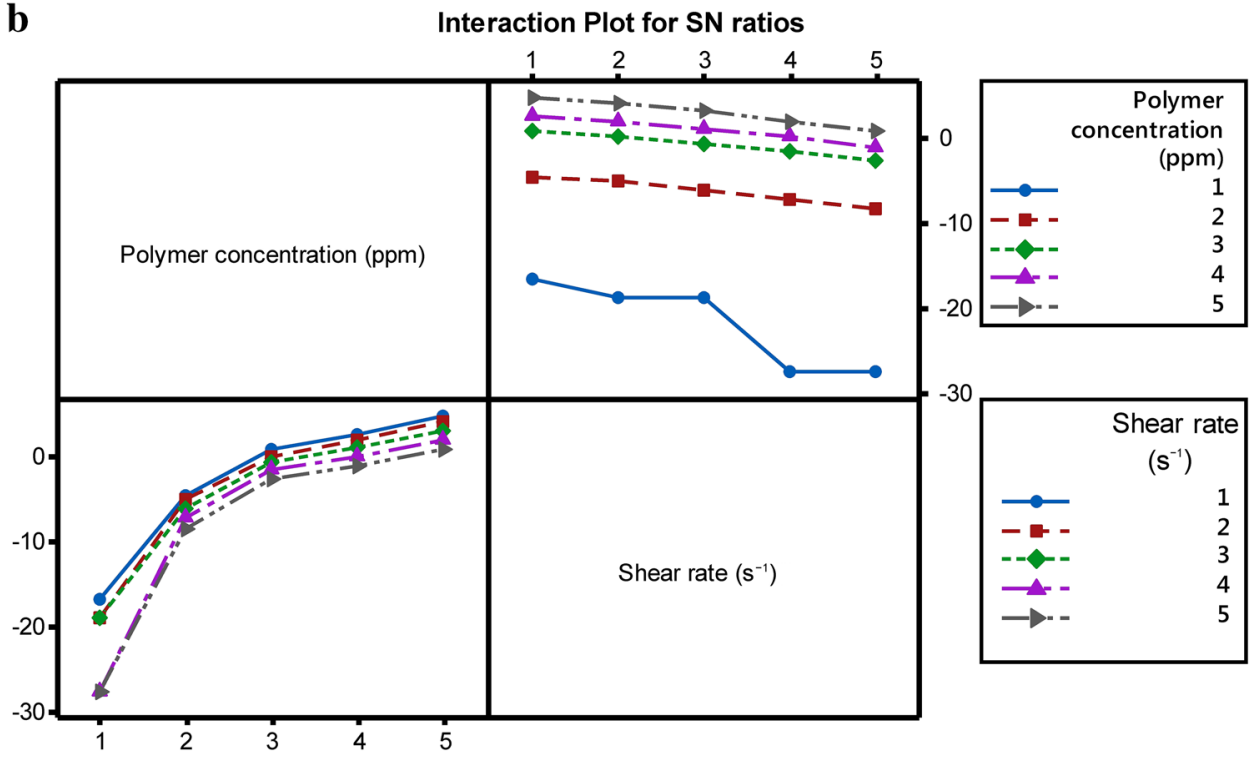

Signal-to-noise: Larger is better

\begin{tabular}{llcc}
\hline S. no & Sulfonation degree $(\mathrm{mol} \%)$ & Shear rate $\left(\mathrm{s}^{-1}\right)$ & Viscosity $(\mathrm{mPa} \mathrm{s})$ \\
\hline 1 & $13(1)$ & $10(1)$ & 270.7 \\
2 & $25(2)$ & $10(1)$ & 297.6 \\
3 & $32(3)$ & $10(1)$ & 353.8 \\
4 & $13(1)$ & $31.6849(2)$ & 137.2 \\
5 & $25(2)$ & $31.6849(2)$ & 153.0 \\
6 & $32(3)$ & $31.6849(2)$ & 172.1 \\
7 & $13(1)$ & $100.393(3)$ & 70.1 \\
8 & $25(2)$ & $100.393(3)$ & 78.0 \\
9 & $32(3)$ & $100.393(3)$ & 83.6 \\
10 & $13(1)$ & $315.608(4)$ & 36.7 \\
11 & $25(2)$ & $315.608(4)$ & 41.2 \\
\hline
\end{tabular}

Table 5 Sulfonation degree and shear rate: the order and conditions for the Taguchi design including the coded levels of each parameter 
Table 5 continued

\begin{tabular}{llll}
\hline S. no & Sulfonation degree $(\mathrm{mol} \%)$ & Shear rate $\left(\mathrm{s}^{-1}\right)$ & Viscosity $(\mathrm{mPa} \mathrm{s})$ \\
\hline 12 & $32(3)$ & $315.608(4)$ & 43.4 \\
13 & $13(1)$ & $736.412(5)$ & 23.4 \\
14 & $25(2)$ & $736.412(5)$ & 26.8 \\
15 & $32(3)$ & $736.412(5)$ & 26.8 \\
16 & $13(1)$ & $1000(6)$ & 21.2 \\
17 & $25(2)$ & $1000(6)$ & 22.4 \\
18 & $32(3)$ & $1000(6)$ & 22.4 \\
\hline
\end{tabular}

Fig. 3 Sulfonation degree and shear rate a main effect, b interaction effect $\mathbf{a}$

Main Effects Plot for SN ratios

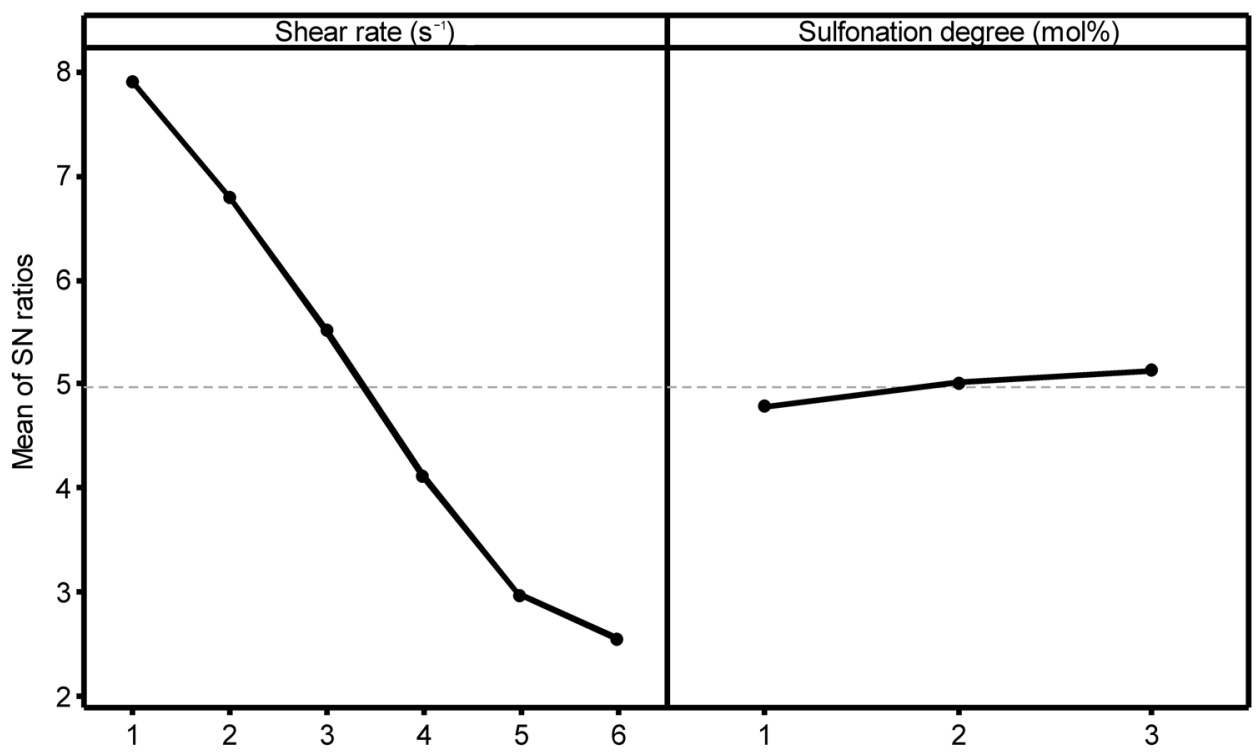

Signal-to-noise: Larger is better

b Interaction Plot for SN ratios

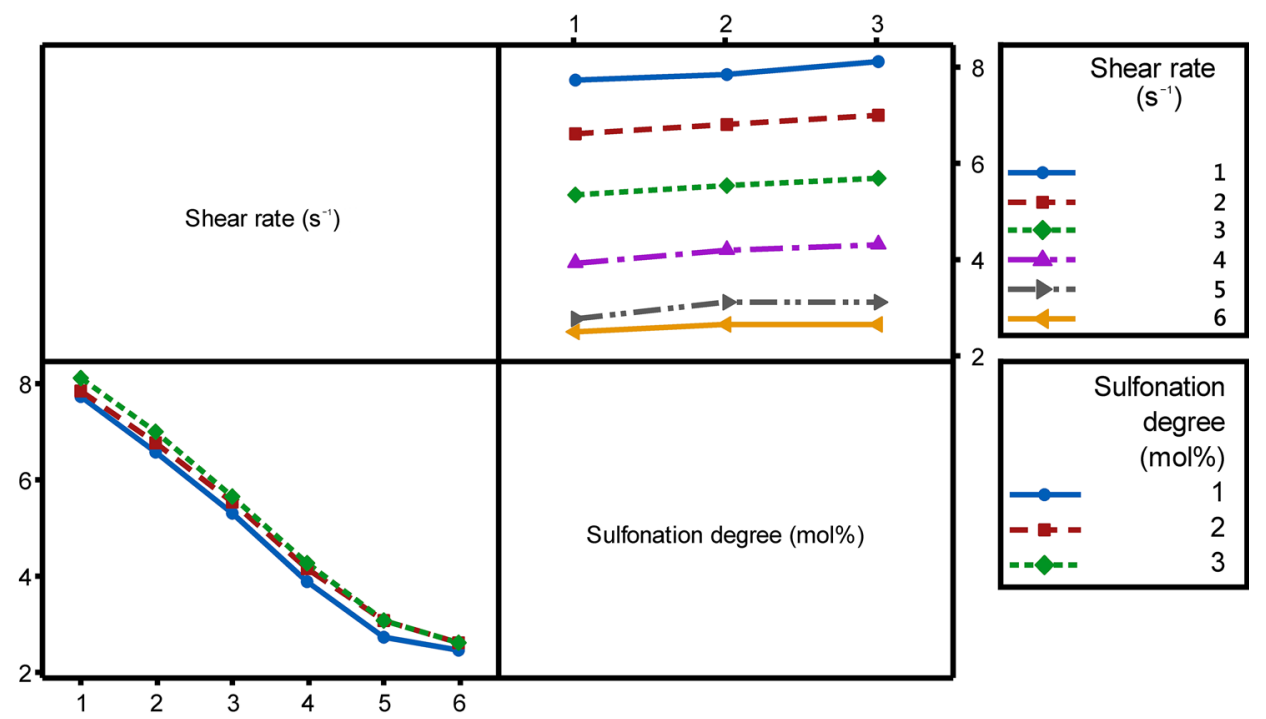

Signal-to-noise: Larger is better 
On the other hand, the interaction plot in Fig. 2b suggests that there might not be a significant interaction due to the polymer concentration $\times$ shear rate. Considering the polymer concentrations between 100 and 1000 ppm, the interaction lines are obviously not parallel which indicates a considerable interaction effect. This is due to the reason that when the polymer concentrations changes between these two levels, the polymer solution's behavior changes from an almost Newtonian fluid to a non-Newtonian fluid. Therefore, the polymer concentration initiates the effect of the shear rate on the polymer solution viscosity. Interestingly, the lines become parallel to each other as the polymer concentration increases higher than 1000 ppm which means that the interaction effect is reduced. However, the overall impact of the polymer concentration $\times$ shear rate is insignificant to the viscosity.

The polymer solution viscosity reduced as the shear rate increased from 10 to $1000\left(\mathrm{~s}^{-1}\right)$ and increased with an increase in the polymer concentration. These findings were consistent with those of other studies (Lewandowska 2007). A viscosity reduction with the shear rate is noticed for pseudo-plastic or shear thinning fluids. The orientation of macromolecules along the stream line of the flow is considered to be the reason for the pseudo-plastic behavior (Ait-Kadi et al. 1987; Ballard et al. 1988; Carreau 1972; Chagas et al. 2004; Ghannam 1999). For all polymers, a higher polymer concentration gives a solution with a higher viscosity. This is because the polymer concentration changes the interaction among the polymer molecules (Rashidi et al. 2010; Sorbie 1991).

Similarly, Table 3 shows the ANOVA results of the polymer solution viscosity. It was observed that the polymer concentration was the more significant parameter affecting solution viscosity as compared to the shear rate. The polymer concentration and the shear rate, individually, affected the polymer viscosity by approximately 94 and $4 \%$, respectively. An error contribution of $2 \%$ was obtained which included all the interaction effects. As the percentage of the interaction was less than or equal to $2 \%$, the insignificant interaction effects were deduced, which were in line with $S$ / $N$ ratio results.

\section{Effect of the sulfonation degree and shear rate on the polymer solution viscosity}

The resultant range of the experimental conditions, including their coded levels, can be observed in Table 5. In this step, the viscosity of sulfonated polyacrylamide polymers in $0.1 \mathrm{wt} \% \mathrm{NaCl}$ as a function of shear rate at different sulfonation degrees and a $5000 \mathrm{ppm}$ polymer concentration at $20{ }^{\circ} \mathrm{C}$ has been considered.
The $S / N$ response graph for the polymer solution viscosity as a function of the sulfonation degree and shear rate is depicted in Fig. 3. The main effects' plot in Fig. 3a suggests that there might be a significant effect associated with the shear rate as compared to the sulfonation degree effect. It is known that increasing the shear rate increases the orientation of macromolecules along the stream line of the flow subsequently decreasing the viscosity. Likewise, the introduction of the sulfonic acid increases the rigidity of the polymer chain (Ballard et al. 1988), thereby causing an increase in the viscosity. But, the change in the viscosity due to the shear rate is greater than the change due to the addition of the sulfonic units. This effect is due to the fact that, for the given conditions, the rigidity which is induced by the addition of the sulfonic units is not enough to resist the reorientation degree imposed by the increasing shear rate.

On the other hand, the interaction plot in Fig. 3b suggests that there might not be a significant interaction due to the sulfonation degree $\times$ shear rate as the lines are almost parallel except for the $13 \%$ sulfonation degree when the

Table $6 \mathrm{NaCl}$ concentration and Shear rate: the order and conditions for the Taguchi design including the coded levels of each parameter

\begin{tabular}{|c|c|c|c|}
\hline S. no & $\mathrm{NaCl}$ conc. (wt\%) & Shear rate $\left(\mathrm{s}^{-1}\right)$ & Viscosity ( $\mathrm{mPa} \mathrm{s})$ \\
\hline 1 & $0.1(1)$ & $10(1)$ & 354.6 \\
\hline 2 & $0.1(1)$ & $31.6228(2)$ & 172.2 \\
\hline 3 & $0.1(1)$ & $108.871(3)$ & 79.4 \\
\hline 4 & $0.1(1)$ & 341.631 (4) & 40.2 \\
\hline 5 & $0.1(1)$ & $1000(5)$ & 21.6 \\
\hline 6 & $1(2)$ & $10(1)$ & 113.4 \\
\hline 7 & $1(2)$ & $31.6228(2)$ & 69.1 \\
\hline 8 & $1(2)$ & $108.871(3)$ & 38.1 \\
\hline 9 & $1(2)$ & $341.631(4)$ & 22.7 \\
\hline 10 & $1(2)$ & $1000(5)$ & 17.5 \\
\hline 11 & $3(3)$ & $10(1)$ & 68.0 \\
\hline 12 & $3(3)$ & $31.6228(2)$ & 47.4 \\
\hline 13 & $3(3)$ & $108.871(3)$ & 29.9 \\
\hline 14 & $3(3)$ & $341.631(4)$ & 19.6 \\
\hline 15 & $3(3)$ & $1000(5)$ & 14.4 \\
\hline 16 & $5(4)$ & $10(1)$ & 58.8 \\
\hline 17 & $5(4)$ & $31.6228(2)$ & 43.3 \\
\hline 18 & $5(4)$ & $108.871(3)$ & 27.8 \\
\hline 19 & $5(4)$ & $341.631(4)$ & 18.6 \\
\hline 20 & $5(4)$ & $1000(5)$ & 13.4 \\
\hline 21 & $10(5)$ & $10(1)$ & 58.8 \\
\hline 22 & $10(5)$ & $31.6228(2)$ & 43.3 \\
\hline 23 & $10(5)$ & $108.871(3)$ & 27.8 \\
\hline 24 & $10(5)$ & $341.631(4)$ & 18.6 \\
\hline 25 & $10(5)$ & $1000(5)$ & 13.4 \\
\hline
\end{tabular}


shear rate is changing from $736\left(\mathrm{~s}^{-1}\right)$ to $1000\left(\mathrm{~s}^{-1}\right)$. The interaction effects are not considerable because almost all the different sulfonation degrees show the same trend with an increasing shear rate.

Similarly, Table 3 shows that the ANOVA results of the polymer solution viscosity. It was observed that the shear rate was the more significant parameter affecting the solution viscosity as compared to the sulfonation degree. The shear rate and the sulfonation degree affected the polymer viscosity by approximately 99 and $0.5 \%$, respectively. As the percentage of the interaction was less than or equal to $0.5 \%$, the insignificant interaction effects were deduced, which were in line with the $S / N$ ratio results.

\section{Effect of the $\mathrm{NaCl}$ concentration and shear rate on the polymer solution viscosity}

The resultant range of experimental conditions, including their coded levels, can be observed in Table 6. In this step, the viscosity of the AN132 as a function of the shear rate and salinity for the $5000 \mathrm{ppm}$ polymer concentration at $20{ }^{\circ} \mathrm{C}$ has been considered.
Fig. $4 \mathrm{NaCl}$ concentration and shear rate a main effect, b interaction effect a

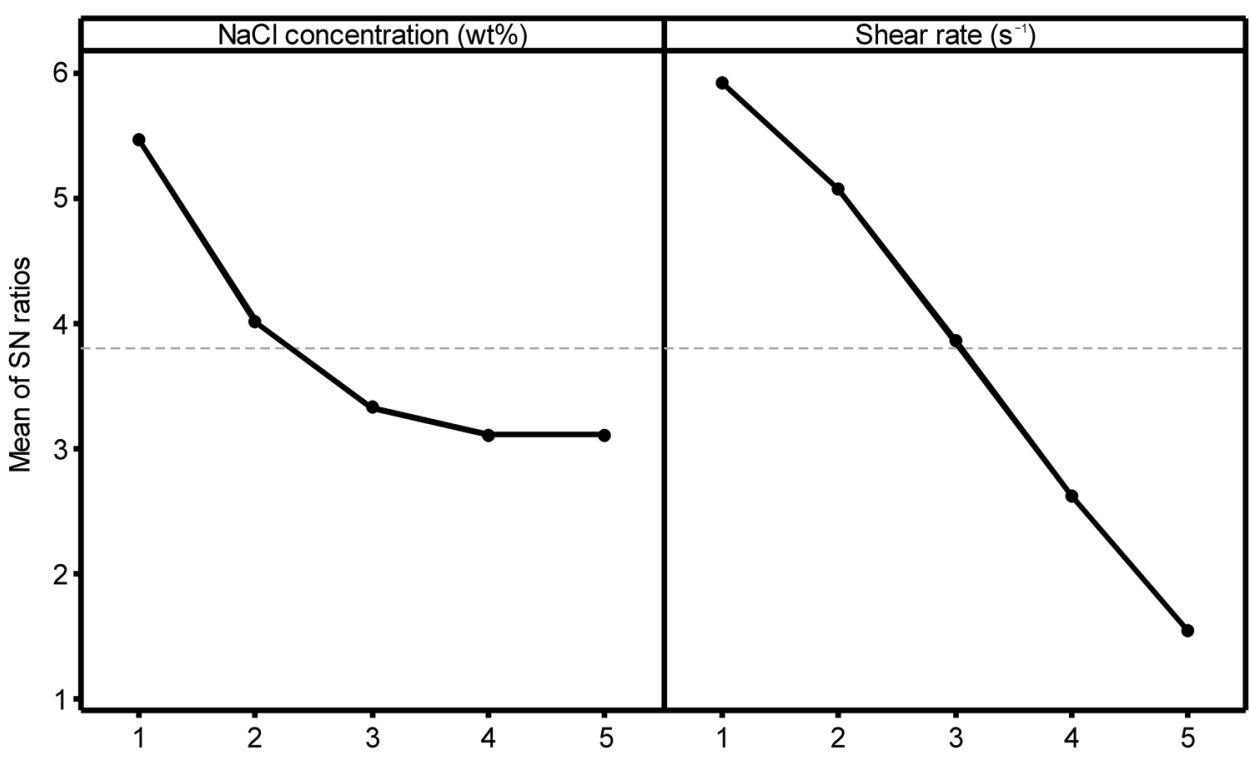

Signal-to-noise: Larger is better

b

Interaction Plot for SN ratios

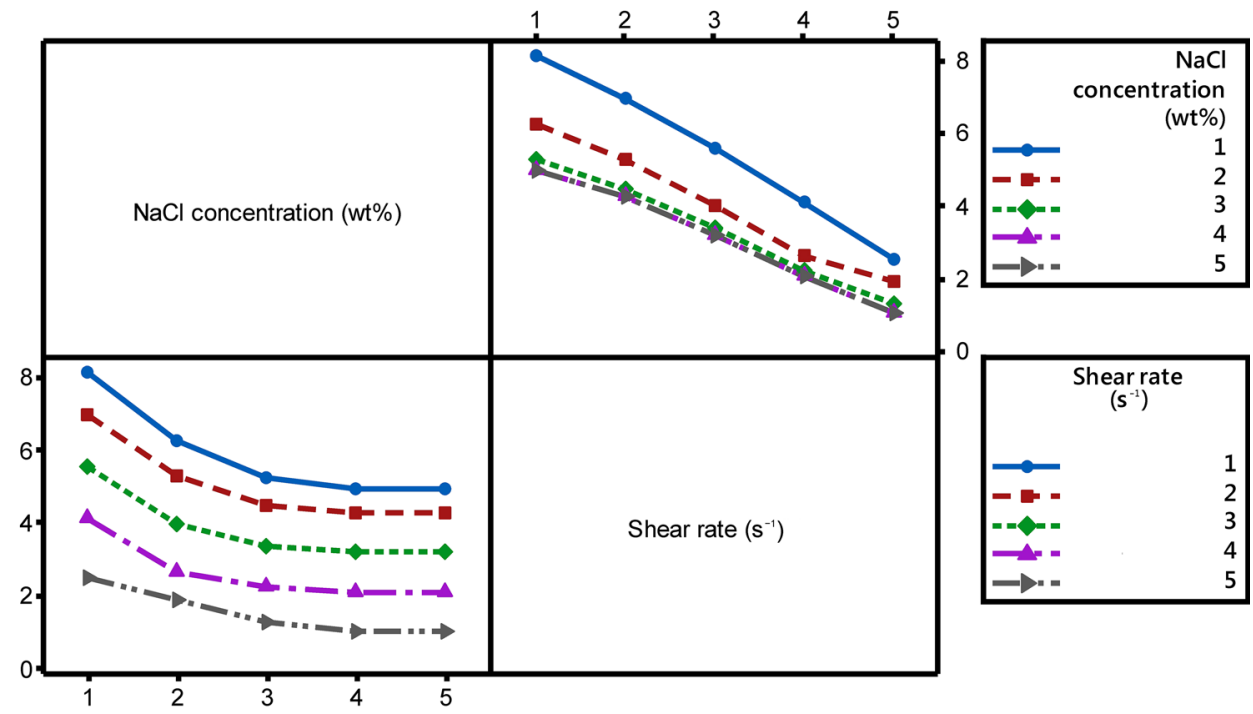

Signal-to-noise: Larger is better

Main Effects Plot for SN ratios 
The $S / N$ response graph for the polymer solution viscosity as a function of salinity and shear rate is depicted in Fig. 4. The main effects' plot in Fig. 4a suggests that there might be a significant effect associated with the Shear rate as compared to the $\mathrm{NaCl}$ concentration. Figure 4a shows that the shear rate has a higher effect than the $\mathrm{NaCl}$ concentration which can be seen by looking at the slope of the lines connecting different levels of each parameter. By increasing the $\mathrm{NaCl}$ concentration, the slope of the line reduced; while by increasing the shear rate, the slope of the line remains almost constant. The reduction of the slope of the $\mathrm{NaCl}$ concentration lowers the average effect of the $\mathrm{NaCl}$ concentration on the solution viscosity. On the other hand, the interaction plot in Fig. $4 \mathrm{~b}$ suggests that there might not be a significant interaction due to the $\mathrm{NaCl}$ concentration $\times$ shear rate because the lines are almost parallel to each other.

Similarly, Table 3 shows the ANOVA results of the polymer solution viscosity. It was observed that the shear rate was the more significant parameter affecting the solution viscosity as compared to the $\mathrm{NaCl}$ concentration. The shear rate and the $\mathrm{NaCl}$ concentration affected the polymer viscosity by approximately 74 and $24 \%$, respectively. An error contribution of $2 \%$ was obtained which included all the interaction effects. As the percentage of the interaction was less than or equal to $2 \%$, the insignificant interaction effects were deduced, which were in line with the $S / N$ ratio results.

The polymer solution viscosity reduced with an increase in the $\mathrm{NaCl}$ concentration and shear rate. These findings were consistent with those of other studies (AitKadi et al. 1987; Chagas et al. 2004; Rashidi et al. 2010). The addition of $\mathrm{NaCl}$ to the polymer solution shielded the charges on the polymer chain. The molecules then coiled up and resulted in a lower polymer solution viscosity (Ait-Kadi et al. 1987; Chagas et al. 2004; Rashidi et al. 2010). The rate of the decrease in the viscosity began to level off after a particular salinity as all charges on the polymer chain had been screened by the $\mathrm{NaCl}$ ions. This phenomenon can be observed in the main effect figure when the $\mathrm{NaCl}$ concentration changed from 5 to $10 \mathrm{wt} \%$.

\section{Effect of the sulfonation degree and $\mathrm{NaCl}$ concentration on the polymer solution viscosity}

The resultant range of the experimental conditions, including their coded levels, can be observed in Table 7. In this step, the viscosity of the sulfonated polyacrylamide polymers as a function of the $\mathrm{NaCl}$ concentration for different sulfonation degrees at a constant shear rate of $100 \mathrm{~s}^{-1}$ at $20{ }^{\circ} \mathrm{C}$ has been considered.
Table 7 Sulfonation degree and $\mathrm{NaCl}$ concentration: the order and conditions for the Taguchi design including the coded levels of each parameter

\begin{tabular}{llrl}
\hline S. no & $\begin{array}{l}\text { Sulfonation } \\
\text { degree }(\mathrm{mol} \%)\end{array}$ & $\begin{array}{l}\text { NaCl conc. } \\
(\mathrm{wt} \%)\end{array}$ & $\begin{array}{l}\text { Viscosity } \\
(\mathrm{mPa} \mathrm{s})\end{array}$ \\
\hline 1 & $5(1)$ & $0.1(1)$ & 47.0 \\
2 & $5(1)$ & $0.5(2)$ & 35.4 \\
3 & $5(1)$ & $1(3)$ & 32.4 \\
4 & $5(1)$ & $5(4)$ & 32.5 \\
5 & $13(2)$ & $0.1(1)$ & 70.8 \\
6 & $13(2)$ & $0.5(2)$ & 49.7 \\
7 & $13(2)$ & $1(3)$ & 40.9 \\
8 & $13(2)$ & $5(4)$ & 28.2 \\
9 & $25(3)$ & $0.1(1)$ & 78.5 \\
10 & $25(3)$ & $0.5(2)$ & 46.3 \\
11 & $25(3)$ & $1(3)$ & 38.1 \\
12 & $25(3)$ & $5(4)$ & 27.0 \\
13 & $32(4)$ & $0.1(1)$ & 83.9 \\
14 & $32(4)$ & $0.5(2)$ & 47.6 \\
15 & $32(4)$ & $1(3)$ & 40.6 \\
16 & $32(4)$ & $5(4)$ & 27.5 \\
\hline
\end{tabular}

The $S / N$ response graph for the polymer solution viscosity as a function of the polymer concentration and sulfonation degree is depicted in Fig. 5.The main effects' plot in Fig. 5a suggests that the $\mathrm{NaCl}$ concentration affected the polymer solution viscosity higher than the sulfonation degree. The obvious effect of changing the salt concentration in a solution of a flexible polyelectrolyte is that the latter will expand in a low salt concentration. The mutual repulsion of the charges along the chain leads to a high polymer solution viscosity. While the polymer contracts in a high salt concentration, leading to a low solution viscosity (Sorbie 1991).

On the other hand, the interaction plots in Fig. 5b suggests that there might be a significant interaction due to the $\mathrm{NaCl}$ concentration $\times$ sulfonation degree. The lines intersect because at the lowest sulfonation degree, i.e., $5 \mathrm{~mol} \%$, almost no viscosity change is observed between 1 and $5 \mathrm{wt} \% \mathrm{NaCl}$. At a $1 \mathrm{wt} \% \mathrm{NaCl}$ concentration, almost all the charges on the polymer chain have been screened by the $\mathrm{NaCl}$ ions; and after this salinity, the viscosity decreasing rate levels off. While for the polymer with the $32 \mathrm{~mol} \%$ sulfonation degree further decreasing viscosity is observed between 1 and $5 \mathrm{wt} \%$ as there are charges which have not been screened by the $\mathrm{NaCl}$ ions.

Similarly, Table 3 shows the ANOVA results of the polymer solution viscosity. It was observed that the $\mathrm{NaCl}$ concentration was the more significant parameter affecting the solution viscosity as compared to the sulfonation degree. 
Fig. 5 Sulfonation degree and $\mathrm{NaCl}$ concentration a main effect, $\mathbf{b}$ interaction effect a

Main Effects Plot for SN ratios

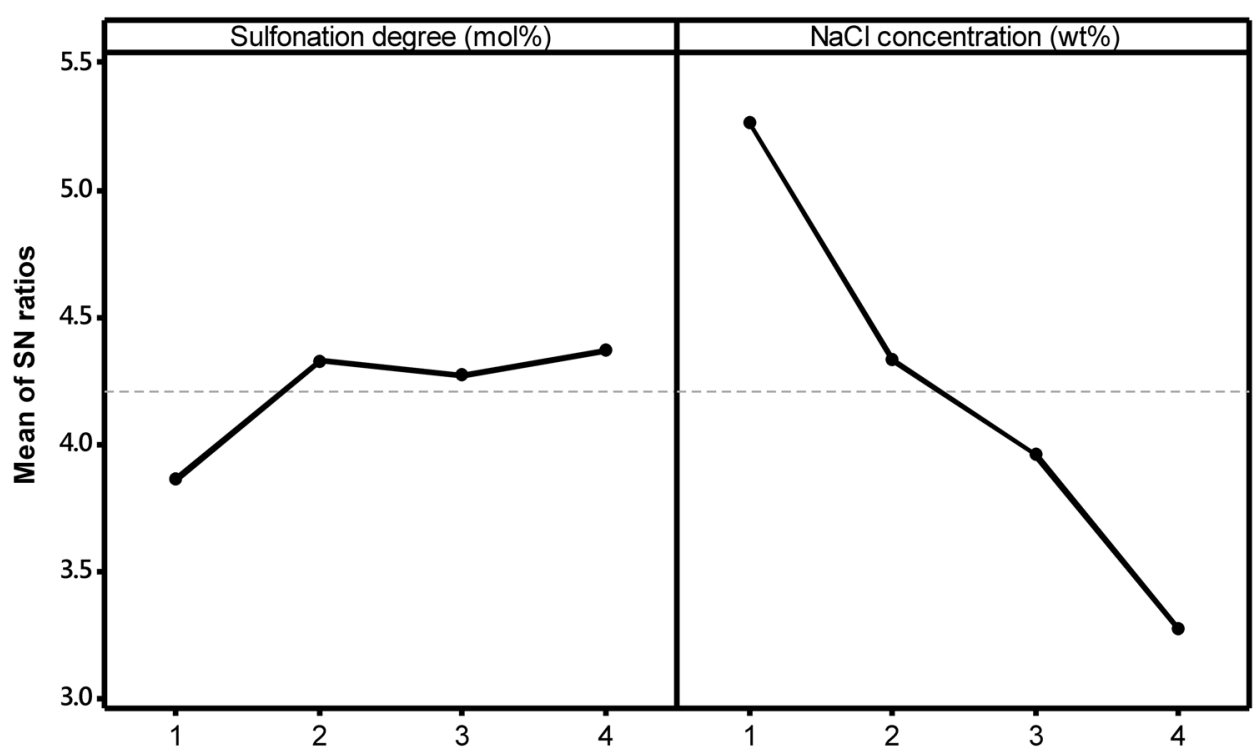

Signal-to-noise: Larger is better

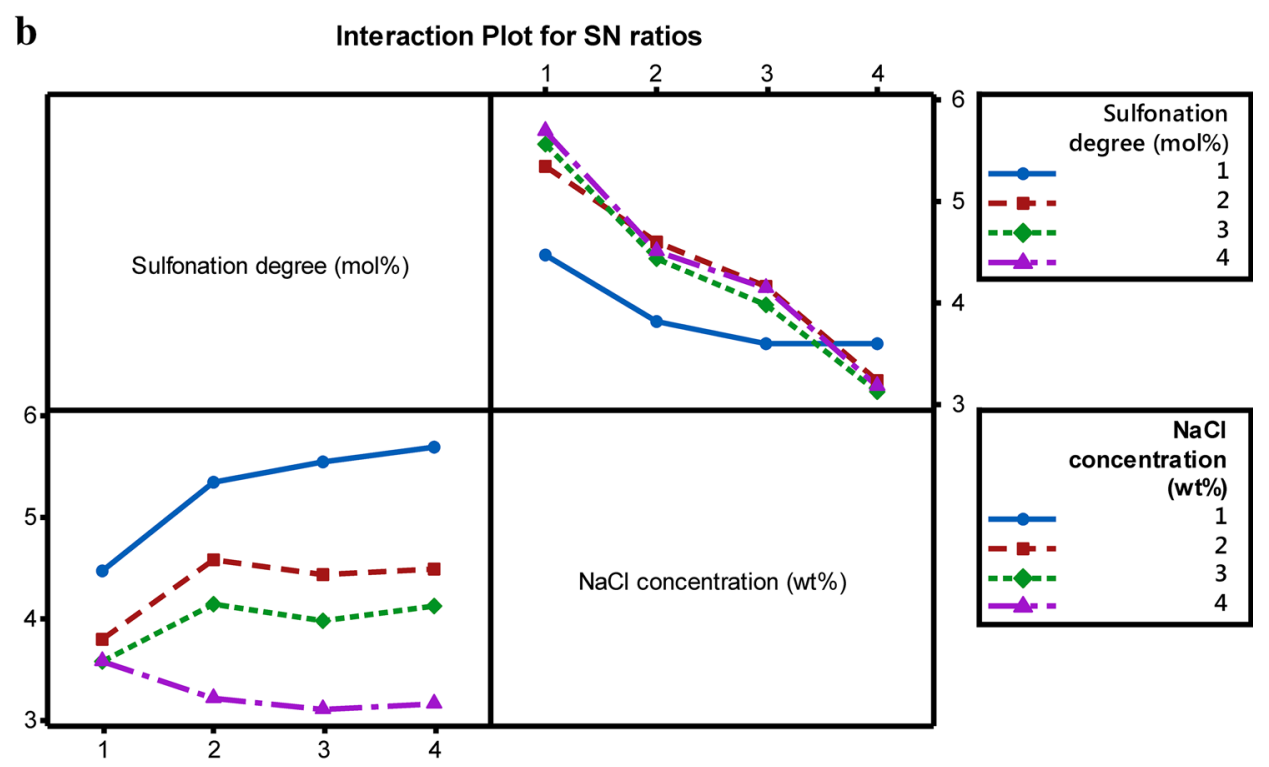

Signal-to-noise: Larger is better

\begin{tabular}{lclc}
\hline S. no & Sulfonation degree $(\mathrm{mol} \%)$ & Polymer concentration $(\mathrm{ppm})$ & Viscosity $(\mathrm{mPa} \mathrm{s})$ \\
\hline 1 & $5(1)$ & $1500(1)$ & 6.2 \\
2 & $5(1)$ & $2500(2)$ & 12.7 \\
3 & $5(1)$ & $5000(3)$ & 42.7 \\
4 & $13(2)$ & $1500(1)$ & 9.0 \\
5 & $13(2)$ & $2500(2)$ & 17.9 \\
6 & $13(2)$ & $5000(3)$ & 61.5 \\
7 & $32(3)$ & $1500(1)$ & 9.2 \\
8 & $32(3)$ & $2500(2)$ & 18.8 \\
9 & $32(3)$ & $5000(3)$ & 59.7 \\
\hline
\end{tabular}

Table 8 Polymer concentration and sulfonation degree: the order and conditions for the Taguchi design including the coded levels of each parameter 
The $\mathrm{NaCl}$ concentration and the sulfonation degree affected the polymer viscosity by approximately 83 and $6.7 \%$. The error contribution of $10 \%$ also included the interaction effect and, therefore, is a considerable value. This is a highly noteworthy effect of the interaction which needs to be taken into account. The polymer solution viscosity increased with the increase in the sulfonation degree, and reduced as the $\mathrm{NaCl}$ concentration increased from 0.1 to $5 \mathrm{wt} \%$, as discussed previously. However, the slight reduction of the polymer solution viscosity in the sulfonation degree
$25 \mathrm{~mol} \%$ could be too small to be significant and could be accounted for in the experimental errors.

\section{Effect of the sulfonation degree and polymer concentration on the polymer solution viscosity}

The resultant range of the experimental conditions, including their coded levels, can be observed in Table 8 . In this step, the viscosity of the sulfonated polyacrylamide polymers as a function of the sulfonation degree at
Fig. 6 polymer concentration and sulfonation degree a main effect, b interaction effect a

Main Effects Plot for SN ratios

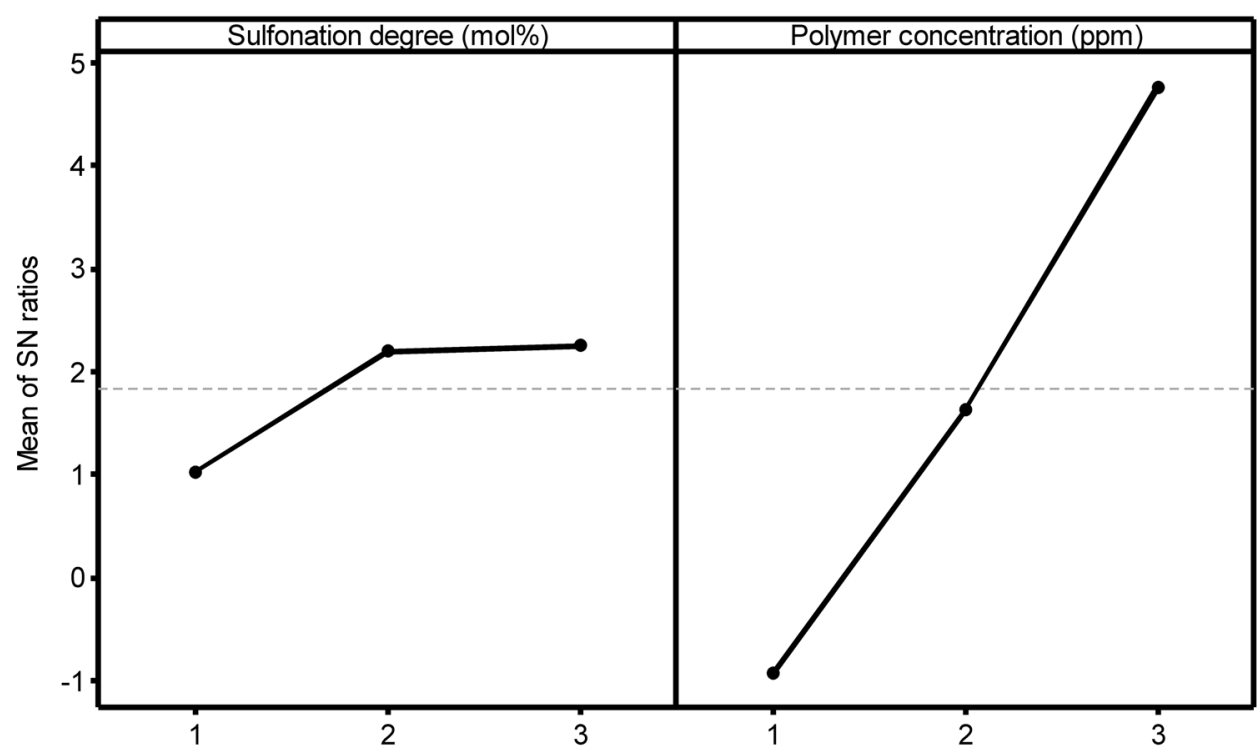

Signal-to-noise: Larger is better

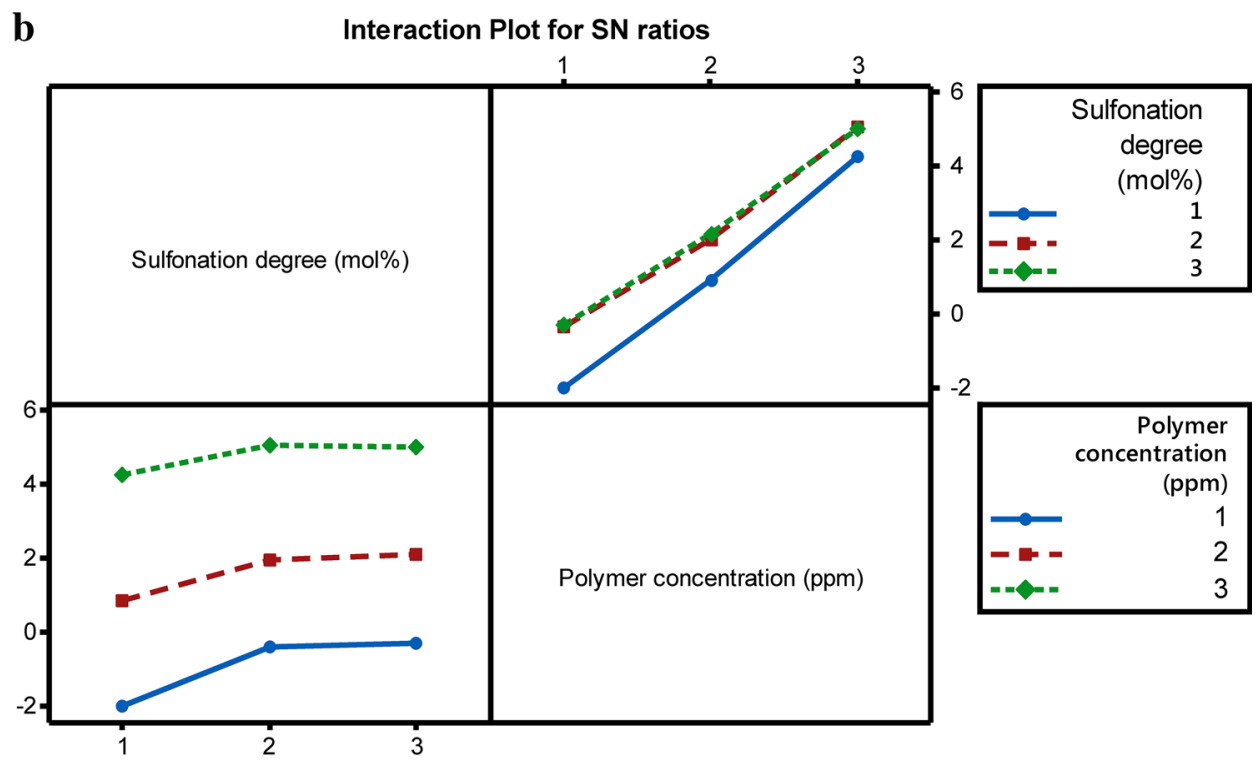

Signal-to-noise: Larger is better 
different polymer concentrations and a constant shear rate of $100 \mathrm{~s}^{-1}$ at $20{ }^{\circ} \mathrm{C}$ has been considered. The $S / N$ response graph for the polymer solution viscosity as a function of the polymer concentration and $\mathrm{NaCl}$ concentration is depicted in Fig. 6. The main effects' plot in Fig. 6a suggests that there might be a significant effect associated with the polymer concentration as compared to the sulfonation degree. On the other hand, the parallel lines in the interaction plot of Fig. $6 \mathrm{~b}$ suggests that there might not be a significant interaction due to the polymer concentration $\times$ sulfonation degree. For each sulfonation degree, an increase in the polymer concentration resulted in the same trend with no drastic changes and, therefore, hints at almost no significant interaction.

Similarly, Table 3 shows the ANOVA results of the polymer solution viscosity. It was observed that the polymer concentration was the more significant parameter affecting the solution viscosity as compared to the sulfonation degree. The polymer concentration and the sulfonation degree affected the polymer viscosity by approximately 94 and $5.5 \%$, respectively. An error contribution of $0.5 \%$ was obtained which included all the interaction effects. As the percentage of the interaction was less than or equal to $0.5 \%$, the insignificant interaction effects were deduced, which were in line with $S / N$ ratio results.

\section{Effect of the molecular weight and $\mathrm{NaCl}$ concentration on the polymer solution viscosity}

The resultant range of the experimental conditions, including their coded levels, can be observed in Table 9. In this step, the viscosity of a typical $25 \mathrm{~mol} \%$ sulfonated polyacrylamide polymer sample as a function of molecular weight in different $\mathrm{NaCl}$ concentrations at $20{ }^{\circ} \mathrm{C}$ has been considered.

Table 9 Molecular weight and $\mathrm{NaCl}$ concentration: the order and conditions for the Taguchi design including the coded levels of each parameter

\begin{tabular}{llrl}
\hline S. no & $\begin{array}{l}\text { Molecular } \\
\text { weight }(\mathrm{mDa})\end{array}$ & $\begin{array}{l}\mathrm{NaCl} \text { concentration } \\
(\mathrm{wt} \%)\end{array}$ & $\begin{array}{l}\text { Viscosity } \\
(\mathrm{mPa} \mathrm{s})\end{array}$ \\
\hline 1 & $2(1)$ & $0.1(1)$ & 63.7 \\
2 & $2(1)$ & $1(2)$ & 14.6 \\
3 & $2(1)$ & $5(3)$ & 9.8 \\
4 & $8(2)$ & $0.1(1)$ & 77.9 \\
5 & $8(2)$ & $1(2)$ & 37.4 \\
6 & $8(2)$ & $5(3)$ & 26.3 \\
7 & $12(3)$ & $0.1(1)$ & 90.1 \\
8 & $12(3)$ & $1(2)$ & 46.4 \\
9 & $12(3)$ & $5(3)$ & 34.2 \\
\hline
\end{tabular}

The $S / N$ response graph for the polymer solution viscosity as a function of the $\mathrm{NaCl}$ concentration and sulfonation degree is depicted in Fig. 7. The main effects' plot in Fig. 7a suggests that there might be a significant effect associated with the $\mathrm{NaCl}$ concentration and molecular weight. The interaction plot in Fig. 7b suggests that there might be a significant interaction due to the molecular weight $\times \mathrm{NaCl}$ concentration since the lines intersect. Notice that the size of the increase in the response, i.e., solution viscosity, when the molecular weight changes, is dependent on the level of the $\mathrm{NaCl}$ concentration. This is because when the polymer chain is shorter, the charges on the polymer chain are easily shielded by salt ions and the molecules coil up and result in a lower polymer solution viscosity as compared to the polymers with a higher molecular weight.

Similarly, Table 3 shows the ANOVA results of the polymer solution viscosity. It was observed that the $\mathrm{NaCl}$ concentration was the more significant parameter affecting the solution viscosity as compared to the molecular weight. The $\mathrm{NaCl}$ concentration and the molecular weight affected the polymer viscosity by approximately 54.4 and $35 \%$, respectively. The error contribution of $10 \%$ also included the interaction effect and, therefore, is a considerable value. This is a highly noteworthy effect of the interaction which needs to be taken into account.

The polymer solution viscosity increased with an increase in the molecular weight and reduced as the $\mathrm{NaCl}$ concentration increased from 0.1 to $5 \mathrm{wt} \%$. These findings were consistent with those of other studies (Lewandowska 2007). For all the polymers, the higher the molecular weight, the higher was the solution viscosity. This is because the molecular weight directly affected the chain size.

\section{Conclusion}

The Taguchi method was successfully used to identify the main effects and interaction effects of different process variables in the polymer solution viscosity of the sulfonated polyacrylamide copolymers. This is the first time that interactions between the parameters in a polymer solution viscosity process have been studied. Two strong interactions were found: (1) $\mathrm{NaCl}$ concentration and sulfonation degree and (2) molecular weight and $\mathrm{NaCl}$ concentration. The Taguchi method is an efficient and effective method for investigating parameter sensitivity and interactions. The following specific conclusions have been made from this work.

- The most important parameter with the respect to the polymer solution viscosity is the polymer

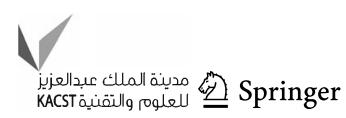


Fig. 7 Molecular weight and $\mathrm{NaCl}$ concentration a main effect, $\mathbf{b}$ interaction effect $\mathbf{a}$ Main Effects Plot for SN ratios

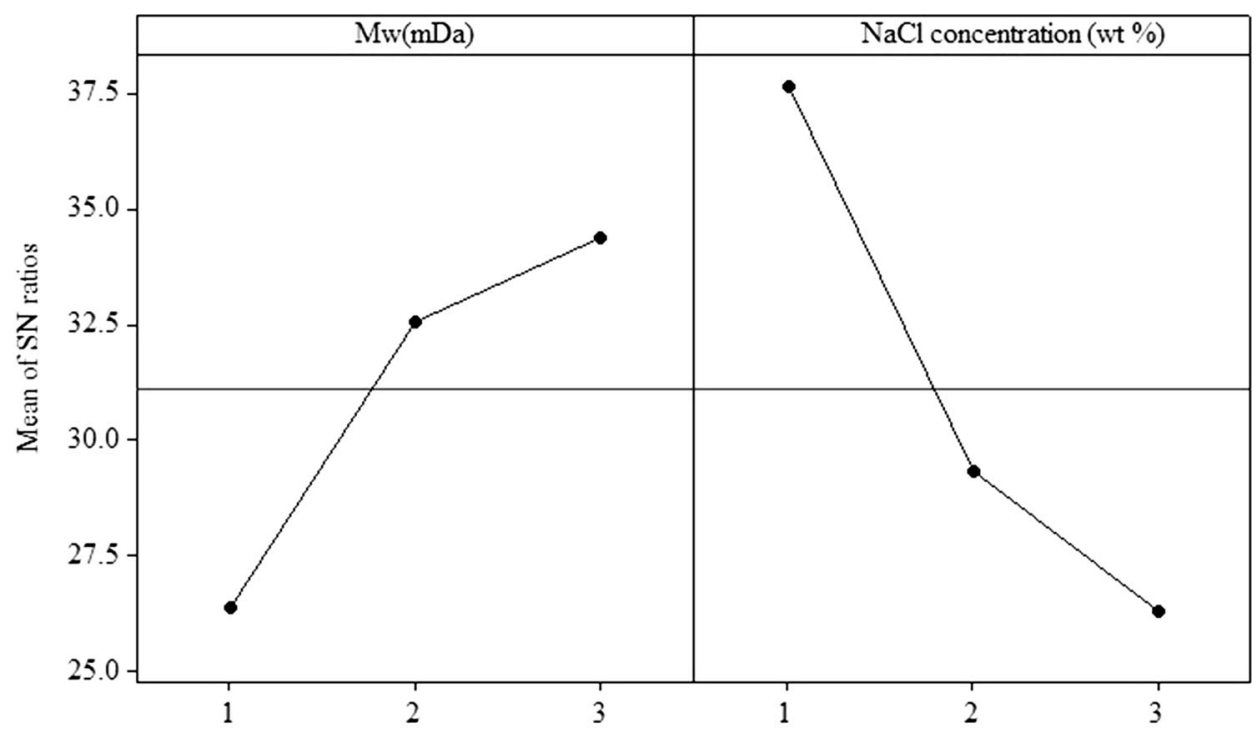

Signal-to-noise: Larger is better

b Interaction Plot for $\mathrm{SN}$ ratios

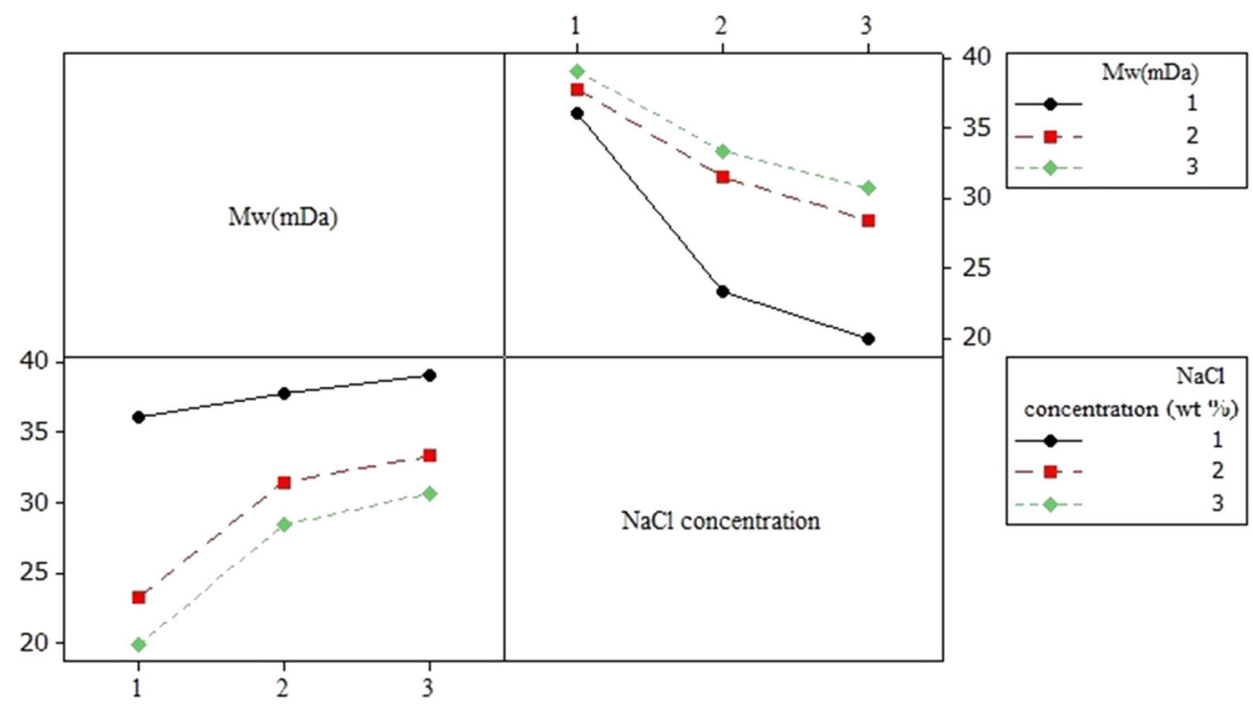

Signal-to-noise: Larger is better concentration; as, the polymer concentration shows the contribution in the order of $94 \%$. Thus, the polymer solution viscosity can be improved by controlled change of the polymer concentration.

- ANOVA was successfully carried out to obtain the contribution percentage of the main parameters and their interaction. Remarkably, the ability to detect the effect of each parameter is commensurate with that of Taguchi's method.

- An extension of this work may include a broader range of operating conditions while giving special consideration to other potential factors that can alter the investigated variables. Also, given that this work's experimental plan has been designed to evaluate each two-factor interaction separately; the next step may be to validate the applicability of the Taguchi design by considering more than two variable interactions at a time.

Open Access This article is distributed under the terms of the Creative Commons Attribution 4.0 International License (http:// creativecommons.org/licenses/by/4.0/), which permits unrestricted use, distribution, and reproduction in any medium, provided you give appropriate credit to the original author(s) and the source, provide a 
link to the Creative Commons license, and indicate if changes were made.

\section{References}

Ait-Kadi A, Carreau PJ, Chauveteau G (1987) Rheological properties of partially hydrolyzed polyacrylamide solutions (1978-present). J Rheol 31:537-561. doi:10.1122/1.549959

Ballard MJ, Buscall R, Waite FA (1988) The theory of shearthickening polymer solutions. Polymer 29:1287-1293. doi:10. 1016/0032-3861(88)90058-4

Bendell A, Disney J, Pridmore WA (1989) Taguchi methods: applications in world industry. IFS. Berlin

Carreau PJ (1972) Rheological equations from molecular network theories. Trans Soc Rheol (1957-1977) 16:99-127. doi:10.1122/ 1.549276

Chagas BS, Machado DLP, Haag RB, De Souza CR, Lucas EF (2004) Evaluation of hydrophobically associated polyacrylamide-containing aqueous fluids and their potential use in petroleum recovery. J Appl Polym Sci 91:3686-3692. doi:10.1002/app. 13628

Dong H, Fang S, Wang D, Wang J, Liu ZL, Hou W (2008) Review of practical experience \& management by polymer flooding at Daqing. In: SPE symposium on improved oil recovery, Tulsa, Oklahoma, USA 20-23 April 2008. Society of Petroleum Engineers

Ghannam MT (1999) Rheological properties of aqueous polyacrylamide/ $\mathrm{NaCl}$ solutions. J Appl Polym Sci 72:1905-1912. doi:10. 1002/(SICI)1097-4628(19990628)72:14<1905:AID-APP11>3. $0 . \mathrm{CO} ; 2-\mathrm{P}$

Han M, Xiang W, Zhang J, Jiang W, Sun F (2006) Application of EOR technology by means of polymer flooding in Bohai oilfields. In: Paper presented at the international oil and gas conference and exhibition in China. Beijing, China

Levitt D, Pope GA (2008) Selection and screening of polymers for enhanced-oil recovery. In: Paper presented at the SPE symposium on improved oil recovery, Tulsa, Oklahoma, USA, 20-23 April 2008
Lewandowska K (2007) Comparative studies of rheological properties of polyacrylamide and partially hydrolyzed polyacrylamide solutions. J Appl Polym Sci 103:2235-2241. doi:10.1002/app. 25247

Luo JH, Liu YZ, Zhu P (2006) Polymer solution properties and displacement mechanisms. In: Shen PP, Liu YZ, Liu HR (eds) Enhanced oil recovery-polymer flooding. Petroleum Industry, beijing, pp 1-72

Mathews PG (2005) Design of experiments with MINITAB. ASQ Quality, Milwaukee

Montgomery DC (2008) Design and analysis of experiments. Wiley, Hoboken

Nasr-El-Din HA (1992) Flow behavior of alkaline, surfactant and xanthan solutions used for enhanced oil recovery. Revue de l'Institut Français du Pétrole 47:771-791

Needham RB, Doe PH (1987) Polymer flooding. Rev Soc Petrol Eng 39:1503-1507. doi:10.2118/17140-PA

Rashidi M, Blokhus AM, Skauge A (2010) Viscosity study of salt tolerant polymers. J Appl Polym Sci 117:1551-1557. doi:10. 1002/app.32011

Rashidi M, Blokhus AM, Skauge A (2011) Viscosity and retention of sulfonated polyacrylamide polymers at high temperature. J Appl Polym Sci 119:3623-3629. doi:10.1002/app.33056

Ross PJ (1996) Taguchi techniques for quality engineering: loss function, orthogonal experiments, parameter and tolerance design. McGraw-Hill, New York

Schulz DN, Kaladas JJ, Maurer JJ, Bock J, Pace SJ, Schulz WW (1987) Copolymers of acrylamide and surfactant macromonomers: synthesis and solution properties. Polymer 28:2110-2115. doi:10.1016/0032-3861(87)90050-4

Sheng J (2011) Modern chemical enhance oil recovery: theory and practice. Gulf Professional, London, Oxford

Sorbie KS (1991) Polymer-improved oil recovery. Blackie, Glasgow

Taguchi G (1987) System of experimental design: engineering methods to optimize quality and minimize costs, vol 1 . UNIPUB/Kraus International Publications, Oregon 